\title{
Chromatin modification and NBS1: their relationship in DNA double-strand break repair
}

\author{
Yuichiro Saito, Hui Zhou and Junya Kobayashi* \\ Department of Genome Repair Dynamics, Radiation Biology Center, Kyoto University, \\ Yoshidakonoecho, Sakyoku, Kyoto 606-8501, Japan
}

(Received 8 February 2015, accepted 2 June 2015; J-STAGE Advance published date: 25 November, 2015)

The importance of chromatin modification, including histone modification and chromatin remodeling, for DNA double-strand break (DSB) repair, as well as transcription and replication, has been elucidated. Phosphorylation of H2AX to $\gamma$ $\mathrm{H} 2 \mathrm{AX}$ is one of the first responses following DSB detection, and this histone modification is important for the DSB damage response by triggering several events, including the accumulation of DNA damage response-related proteins and subsequent homologous recombination (HR) repair. The roles of other histone modifications such as acetylation, methylation and ubiquitination have also been recently clarified, particularly in the context of HR repair. NBS1 is a multifunctional protein that is involved in various DNA damage responses. Its recently identified binding partner RNF20 is an E3 ubiquitin ligase that facilitates the monoubiquitination of histone $\mathrm{H} 2 \mathrm{~B}$, a process that is crucial for recruitment of the chromatin remodeler SNF2h to DSB damage sites. Evidence suggests that SNF2h functions in $\mathrm{HR}$ repair, probably through regulation of end-resection. Moreover, several recent reports have indicated that SNF2h can function in HR repair pathways as a histone remodeler and that other known histone remodelers can also participate in DSB damage responses. On the other hand, information about the roles of such chromatin modifications and NBS1 in non-homologous end joining (NHEJ) repair of DSBs and stalled fork-related damage responses is very limited; therefore, these aspects and processes need to be further studied to advance our understanding of the mechanisms and molecular players involved.

Key words: chromatin, DNA double-strand break, DNA repair, histone modification, NBS1

\section{INTRODUCTION}

DNA double-strand breaks (DSBs) are often generated in genomic DNA upon exposure to ionizing radiation (IR) or DNA-damaging agents, such as bleomycin and neocarzinostatin; alternatively, they are due to the stalling or collapse of DNA replication forks triggered by several genotoxic stress-causing factors such as ultraviolet (UV) radiation, environmental toxins or reactive oxidative species (ROS) (O'Driscoll and Jeggo, 2006). Unrepaired DSBs have dangerous consequences, such as the induction of genome instability and promotion of apoptosis or tumorigenesis. Hence, cells have developed mechanisms in order to immediately recognize DSBs, allow DNA damage-related factors to access them, and then activate DNA damage responses (DDRs) such as cell cycle checkpoints

\footnotetext{
Edited by Hiroshi Iwasaki

* Corresponding author. E-mail: jkobayashi@house.rbc.kyoto-u.ac.jp DOI: http://doi.org/10.1266/ggs.15-00010
}

and DNA repair mechanisms.

The eukaryotic genome is formed of the basal packaging units of chromatin, nucleosomes, and each nucleosome consists of $147 \mathrm{bp}$ of DNA wrapped around a histone octamer containing two copies each of histones H2A, H2B, H3 and H4 (McGhee and Felsenfeld, 1980). Nucleosomes are further packaged into stable chromatin structures by undergoing higher-order folding and condensation, to eventually form chromosomes. As such stable chromatin structure impedes accessibility for DNA-modifying factors for replication, transcription and repair, cells have evolved various mechanisms to mark and modify the chromatin landscape, including histone modifications and local recruitment of chromatin remodeling factors, before activation of DNA-modifying machinery (EhrenhoferMurray, 2004). Because the initiation of DDRs such as cell cycle checkpoints and DNA repair requires DDRrelated factors to access and accumulate at DNA damage sites, both the modification of histones and remodeling of chromatin structure may have important roles in the 
DDR.

Radiation-hypersensitive genetic disorders have been studied to clarify the mechanisms of the previously mentioned DDRs. Ataxia telangiectasia, caused by defects in the ataxia telangiectasia mutated $(A T M)$ gene, is prominent among these disorders, and is related to Nijmegen breakage syndrome (NBS) (Shiloh, 1997; Tauchi et al., 2002b). NBS is an autosomal recessive genetic disorder characterized by immunodeficiency, microcephaly, growth retardation and a high frequency of lymphoid malignancies (Tauchi et al., 2002b; Kobayashi et al., 2004). Cells from NBS patients exhibit a highly elevated sensitivity to ionizing radiation (IR), chromosome instability and abnormal cell cycle checkpoints (Weemaes et al., 1981; Tauchi et al., 2002b; Kobayashi et al., 2004). The gene mutated in NBS is NBS1 (NBN/Nibrin), which has been mapped to chromosome $8 \mathrm{q} 21-24$. It is $50 \mathrm{~kb}$ in size with 16 exons (Tauchi et al., 2002b; Kobayashi et al., 2004) and is widely conserved in eukaryotes. The NBS1 protein interacts with several functional proteins, including ATM, and these interactions are vital for various DDRs. Several years ago, we found that NBS1 physically and functionally interacts with the histone modification enzyme RNF20 and the chromatin remodeler-like factor nucleolin, and these interactions play a key role in ATMdependent cell cycle checkpoint pathways and DSB repair (mainly homologous recombination (HR) repair) (Nakamura et al., 2011; Kobayashi et al., 2012). In this review, we mainly focus on the functions of NBS1 and its relationship with histone modification and chromatin remodeling in DDRs induced by DSBs.

\section{Nijmegen breakage syndrome causative gene:} human NBS1 The gene product of human NBS1 is a 754-amino acid (a.a.) protein that contains several functional domains, mainly located in the $\mathrm{N}$ and $\mathrm{C}$ termini (Fig. 1). The $\mathrm{N}$ terminus includes a forkhead-associated (FHA) domain (a.a. 20-108) and two BRCA1 C terminus (BRCT) domains (BRCT1, a.a. 111-197; BRCT2, a.a. 219327). The FHA domain has been shown to be a proteinprotein interaction motif, and the BRCT domain is also thought to be an interaction domain; these motifs bind to phosphorylated regions of specific proteins (Durocher et al., 1999). Indeed, we previously reported an interaction between the FHA and BRCT1 domains of NBS1 and phosphorylated histone H2AX that was responsible for recruitment of NBS1 to the vicinity of DSB sites (Kobayashi et al., 2002). The mediator of DNA-damage checkpoint 1 (MDC1) is another binding partner of NBS1. When MDC1 is phosphorylated by casein kinase 2 , it can interact with the FHA domain of NBS1, and this interaction may be important for the accumulation of NBS1 at DSB sites (Chapman and Jackson, 2008; Melander et al., 2008).

On the other hand, several proteins can directly interact with the C-terminal sequence of NBS1, which shows no similarity to any known protein apart from the presence of several short motifs that are broadly conserved among mammals. Yeast two-hybrid experiments have demonstrated that one of these motifs in the $\mathrm{C}$ terminus region (a.a. 682-693) is vital for direct binding to the DSB repair protein MRE11, a human ortholog of yeast meiotic recombination 11 (Tauchi et al., 2001), and MRE11 also directly interacts with RAD50, another DNA repair protein (Rein and Stracker, 2014). These proteins form a stable complex (MRE11/RAD50/NBS1: MRN), allowing nuclear localization of the molecules and facilitating their function in one of the major DDR pathways, HR repair. This complex is widely conserved in eukaryotes (Tauchi et al., 2001). As shown in Fig. 2, the MRN complex is rapidly recruited to DSB ends; HR repair is then initiated via resection of the DSB ends, which results in the creation of more than 30-nucleotide single-stranded DNA (ssDNA) tails, followed by binding of the replication protein A (RPA) complex (Thompson, 2012). The MRN complex, and particularly MRE11, is reported to participate in the resection step of HR along with several DNA nucleases (CtIP [C-terminal binding protein interacting protein], EXO1 and DNA2). RAD51, another DNA repair protein, is then loaded in place of RPA on ssDNA regions; this exchange step is mediated by Rad52 in yeast or BRCA2 in vertebrates, and promotes the initiation of further HR steps (Mimitou and Symington, 2011; Thompson, 2012; Shibata et al., 2014). NBS1- or MRE11-deficient chicken DT40 or human cells showed remarkably decreased HR activity (Tauchi et al., 2002a; Sakamoto et al., 2007), suggesting the importance of the MRN complex in HR repair.

Another conserved motif (a.a. 734-754) at the $\mathrm{C}$ terminus of NBS1 directly interacts with ATM (Bakkenist and Kastan, 2003). NBS patient cells are deficient in the recruitment of ATM to DSB sites when exposed to IR, and show insufficient activation of ATM kinase, suggesting an important role for this interaction between NBS1 and ATM, via this C-terminal motif, in ATM activation (Bakkenist and Kastan, 2003). ATM phosphorylates many types of protein in response to DSB damage, and this phosphorylation contributes to cell cycle checkpoint activation to arrest the cell cycle in damaged cells. Most of the substrates that are phosphorylated by ATM have consensus sequences with SQ/TQ motifs, and these motifs are also found in the central region of NBS1. Specifically, serine residues at positions 278 and 343 are phosphorylated by ATM in response to radiation both in vitro and in vivo (Lim et al., 2000; $\mathrm{Wu}, \mathrm{X}$. et al., 2000), and are highly conserved in vertebrates (Tauchi et al., 2002b). Substituting these phosphorylation sites with alanine residues resulted in the abrogation of the ATM-dependent intra-S checkpoint in response to DSB damage in mammalian cells, which was also observed in the cells of NBS patients (Lim et al., 2000; Wu, X. et al., 2000). These results indicate that NBS1 functions as a signal trans- 


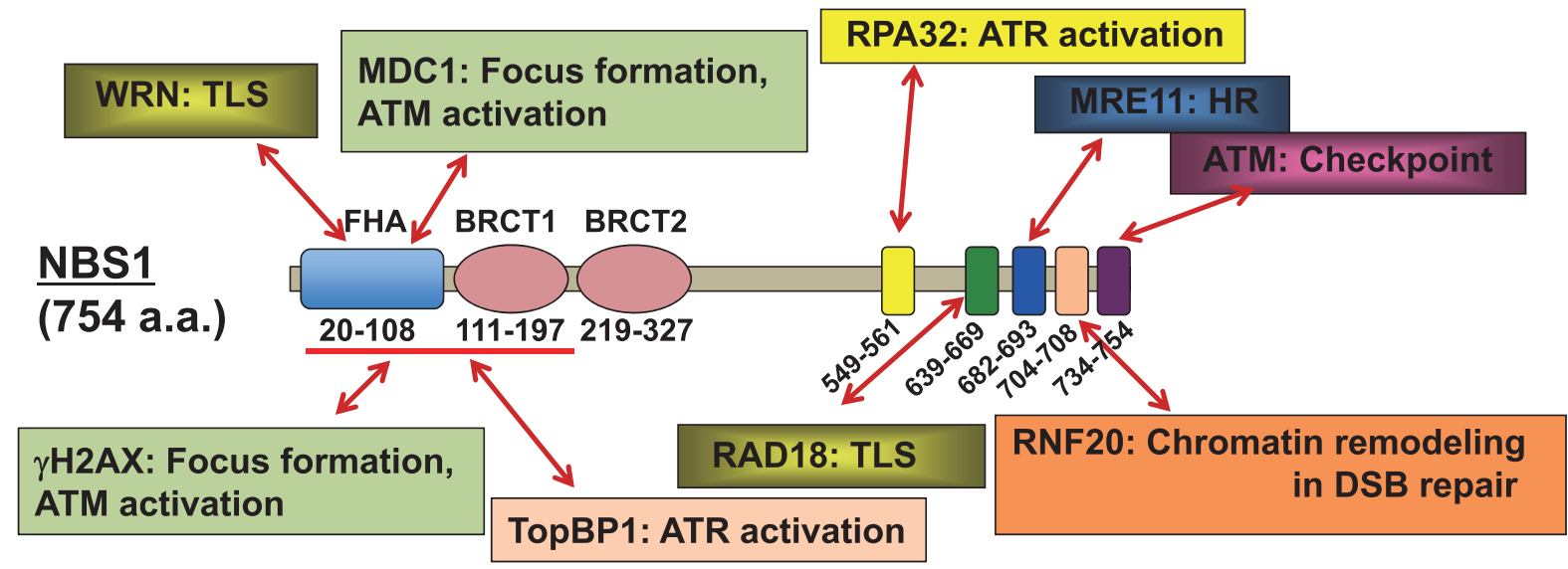

Fig. 1. The structure and protein interactions of human NBS1. NBS1 contains several interaction motifs in the N and C termini. The N-terminal FHA/BRCT domains interact with MDC1, $\gamma$-H2AX, TopBP1 and WRN. The C-terminal motifs are indispensable for binding to MRE11, ATM, RAD18, RNF20 and RPA32. These interactions may be important for the maintenance of genomic stability.

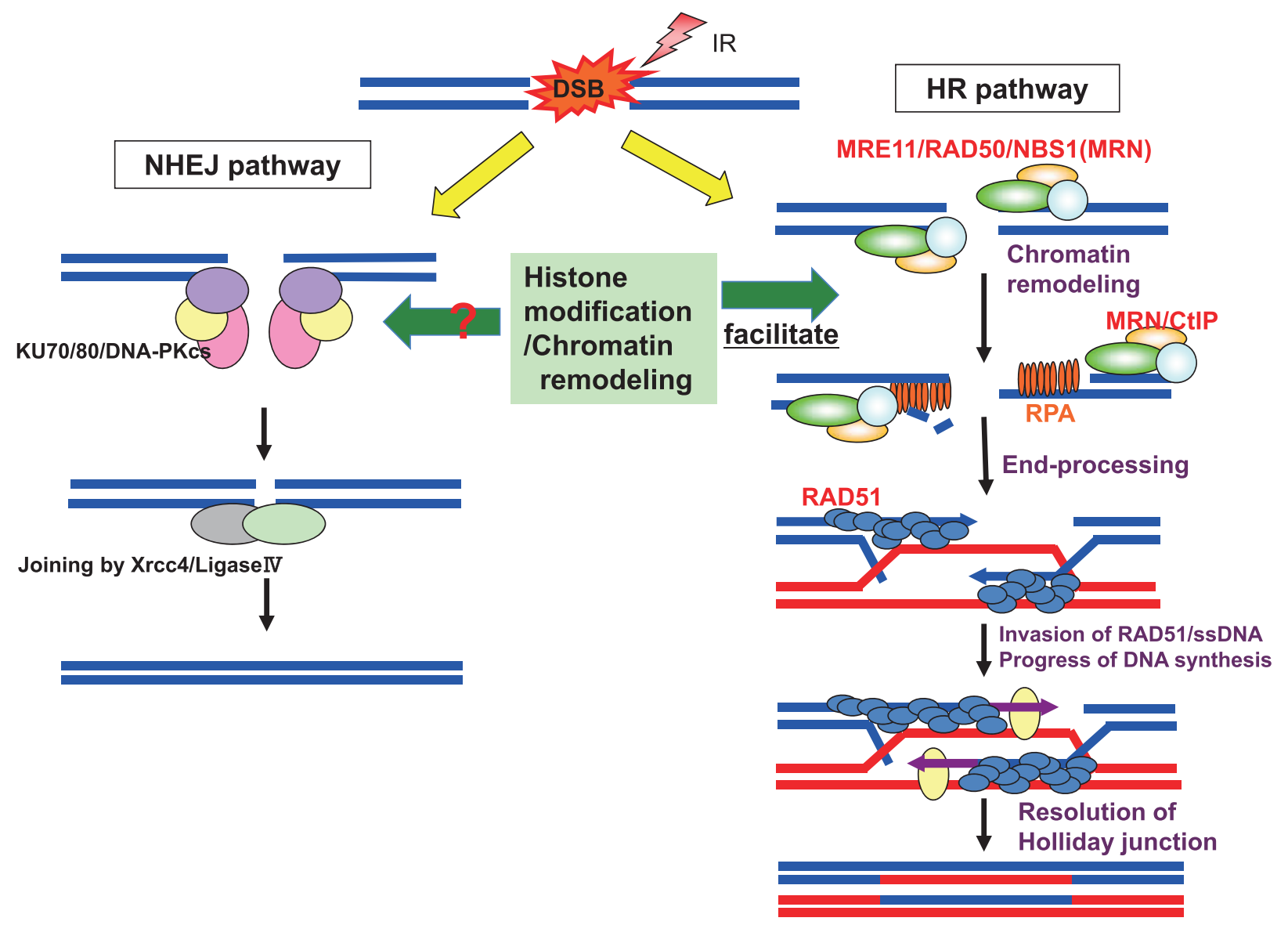

Fig. 2. The function of NBS1 in homologous recombination repair. DNA double-strand breaks (DSBs) are mainly repaired via two pathways: non-homologous end joining (NHEJ) and homologous recombination (HR). NBS1 participates in the HR pathway as a component of the MRN complex. Upon DSB generation, the MRN complex is recruited to DSB sites, and NBS1/RNF20-dependent H2B ubiquitination and SNF2h-dependent chromatin remodeling stimulate the resection of DSB ends (generation of single-strand (ss)DNA ends) by MRN/CtIP and other nucleases. The RPA complex then binds to the ssDNA ends and is subsequently exchanged for RAD51. The RAD51/ssDNA complex invades the complementary template DNA, and DNA synthesis then proceeds until capture of the second end. The resulting double Holliday junction is resolved by specific nucleases, and the HR repair is complete. Other histone modifications such as acetylation and methylation may participate in this pathway. On the other hand, the detailed role of chromatin modifications in NHEJ repair remains unclear. 
ducer for ATM-dependent cell cycle checkpoint activation and as a regulator of ATM kinase.

Furthermore, we previously reported that another two conserved C-terminal motifs contribute to the interaction with RAD18 (an E3 ubiquitin ligase for PCNA) and RNF20. Direct binding of the first of these motifs (a.a. 639-669) with RAD18 was confirmed using recombinant proteins, and the interaction between them increased in response to UV damage (Yanagihara et al., 2011). NBSdeficient human and mouse cells have been shown to be mildly sensitive to UV irradiation; however, NBS patient cells were not defective in nucleotide excision repair (NER) after UV-induced DNA damage (Yanagihara et al., 2011). Translesion synthesis (TLS) of DNA describes another tolerance pathway for UV-induced DNA damage, and is accomplished by Pol $\eta$. When the progression of normal DNA synthesis is stalled at UV-damaged DNA sites, pol $\eta$ can bypass them instead of typical DNA polymerases (Masutani et al., 2000). In UV-irradiated human cells, Pol $\eta$ is recruited to DNA damage sites, presumably at stalled replication forks, and interacts with monoubiquitinated PCNA (Stelter and Ulrich, 2003; Tissier et al., 2004; Watanabe et al., 2004). The monoubiquitination of PCNA is carried out in a RAD6/RAD18dependent manner (Lee and Myung, 2008). Thus, the RAD6/RAD18-dependent monoubiquitination of PCNA is essential for the activation of Poln-dependent TLS at UVinduced DNA damaged sites. We found that NBS1deficient mouse and human cells could not induce PCNA monoubiquitination and had defects in both RAD18 and Pol $\eta$ focus formation following UV irradiation (Yanagihara et al., 2011). As mentioned above, we also found a direct interaction between NBS1 and RAD18 (Yanagihara et al., 2011); therefore, this interaction may be indispensable for activation of RAD18/Pol $\eta$-dependent TLS in response to UV damage.

The second of these motifs (a.a. 704-708) contributes to direct binding between NBS1 and RNF20, a homolog of yeast Bre1 (an E3 ubiquitin ligase for histone H2B). RNF20-dependent ubiquitination may be important for the DDR in mammalian cells (Nakamura et al., 2011). In the next section, we describe this hypothesis in more detail. Furthermore, Shiotani et al. (2013) reported another binding motif (a.a. 549-561) in the C-terminal region of NBS1 for RPA32, one of the three subunits of RPA. This binding may be important for ataxia telangiectasia and Rad3-related protein (ATR) kinase, and we describe this in the sections that follow.

In the case of yeast orthologs (budding yeast Xrs2; fission yeast Nbs1 [spNBS1]), they also form a complex with Mre11 and Rad50 through the N terminus (Tauchi et al., 2001). spNBS1 interacts with Ctp1, the fission yeast homolog of CtIP, through the FHA domain of spNbs1 (Williams et al., 2009; Dodson et al., 2010). Xrs2 interacts with Lif1, the fission yeast homolog of XRCC4, through the FHA domain (Matsuzaki et al., 2012). However, interaction of the yeast ortholog (spNBS1 or Xrs2) with the yeast homolog of RNF20 or Rad18 has not been reported.

Relationship between NBS1 and histone modification in response to DSB damage When DNA DSBs are generated by genomic stress, such as IR, the MRN complex immediately binds with the DSB ends, which leads to recruitment of the PIKK family kinase ATM. Alternatively, the DSB ends may be bound by the KU70/ KU80 heterodimer, which is required for the alternative DSB repair pathway, non-homologous end joining (NHEJ); this binding may recruit another PIKK family kinase, DNA-PK, and subsequently activate it (Gottlieb and Jackson, 1993; Mahaney et al., 2009). These kinases, particularly ATM, phosphorylate serine 139 of $\mathrm{H} 2 \mathrm{AX}$ (to $\gamma$-H2AX) and initiate the chromatin response to DNA damage (Rogakou et al., 1998; Downs et al., 2004; Ataian and Krebs, 2006; Bao, 2011). H2AX is a variant of histone $\mathrm{H} 2 \mathrm{~A}$ and comprises $2-25 \%$ of the H2A complement in mammalian chromatin. $\gamma$-H2AX (H2AX-pS139 in mammals) and $\gamma$-H2A (H2A-pS129ph in yeast) are the most comprehensively investigated histone modification in response to a DSB, and it occurs within minutes of break induction (Rogakou et al., 1998; Kobayashi et al., 2002). Several DDR factors, such as NBS1, MDC1 and BRCA1, interact with $\gamma$-H2AX and subsequently form discrete nuclear foci (Kobayashi et al., 2002; Lou et al., 2006). MDC1 can interact with ATM, and this interaction induces the accumulation of ATM at DSB sites, which amplifies and distributes $\gamma$-H2AX around DSB sites (Lou et al., 2006). H2AX-deficient cells show defects in HR repair and ATM-dependent cell cycle checkpoint activation (Kobayashi et al., 2009; Aydin et al., 2014). In DSB damage-dependent histone modification, $\gamma$-H2AX is of great importance for the effective operation of DSB damage responses.

Histone acetylation and methylation are known to be important for transcription regulation (activation and silencing) and for DNA replication through chromatin remodeling (House et al., 2014). Many reports have suggested that these modifications can occur following generation of DSB damage and contribute to the operation of DDRs. Tamburini and Tyler (2005) showed that acetylation of histone $\mathrm{H} 3$ and $\mathrm{H} 4$ increased at $\mathrm{HO}$ endonuclease-generated DSB sites in yeast, and also showed that the histone acetyltransferases (HATs) Gcn5 and Esa1 were recruited to these damage sites. Downs and her colleagues also reported that Arp4, a subunit of the NuA4 HAT complex, is recruited to HO endonuclease-induced DSB sites and interacts with $\gamma$-H2A directly in yeast (Downs et al., 2004). In mammalian cells, TIP60, the HAT component of the mammalian homolog of the NuA4 HAT complex, can be recruited to a DSB site by a physical 
interaction with the MRN complex and $\gamma$-H2AX (Ikura et al., 2000, 2007; Chailleux et al., 2010). We also reported that TIP60 could acetylate histone H2A, and that this acetylation might be essential for DNA damage-induced focus formation and HR repair (Kobayashi et al., 2010). Recently, histone acetylation at H4-K16 by the MYST family HAT MOF was reported to be required for the recruitment of repair factors, such as MDC1, 53BP1 and BRCA1, to an irradiation-induced DSB site. This acetylation may be a key regulator for DSB repair pathway choice between HR and NHEJ during the S to G2 phase of the cell cycle (Li et al., 2010; Krishnan et al., 2011; Gupta et al., 2014).

In the case of histone methylation, defects of H3-K79 and H3-K36 methylation in yeast cells increased sensitization to IR. In mammalian cells, the methylation of H3-K79 and H4-K20 can be recognized by the presence of the chromatin-associated factor 53BP1 in relaxed chromatin at the DSB (Hartlerode et al., 2012; Wakeman et al., 2012; Hsiao and Mizzen, 2013). SET8 histone methyltransferase (HMT) can induce H4-K20 methylation and recruit 53BP1 to DSB sites (Dulev et al., 2014). Depleting SET8 in mammalian cells attenuated the accumulation of 53BP1 at DSBs and also NHEJ activity, suggesting the importance of H4-K20 methylation for the progression of the 53BP1-dependent NHEJ repair pathway. Another HMT, SETD2 (yeast homolog: SET2), can contribute to DDRs through H3-K36 methylation (Pai et al., 2014; Pfister et al., 2014). Histone H3-K36 has been shown to be methylated by SET2 and acetylated by GCN5, and its methylation reduces chromatin accessibility and promotes the NHEJ repair pathway, while its acetylation increases accessibility and promotes the HR repair pathway. Depletion of SET2 increases acetylation of H3K36, chromatin accessibility and resection, while GCN5 deficiency results in the reverse phenotypes following DSB induction (Pai et al., 2014), suggesting that competition between methylation and acetylation of H3-K36 is important for repair pathway choice between NHEJ and HR. In the case of mammalian SETD2, this enzyme can interact with CtIP, a molecule which has been shown to play a role in the cellular response to DNA damage, and the interaction is important for CtIP recruitment to DSB sites and subsequent resection of DSB ends (Pfister et al., 2014). Depletion of SETD2 was demonstrated to reduce HR activity and increase aberrant resection related to microhomology-mediated end-joining (MMEJ). Thus, methylation of H3-K36 by SETD2 may contribute to the effective resection by $\mathrm{CtIP}$ and subsequent $\mathrm{HR}$ repair in mammals. Moreover, the methylation of H2AX at lysine 134 by the HMT SUV39H2 has been reported. This methylation seems indispensable for H2AX phosphorylation, and overexpression of K134-substituted histone H2AX (A134) enhanced sensitivities to IR, cisplatin and doxorubicin in HeLa cells (Sone et al., 2014). Thus, sev- eral types of histone methylation may contribute to DSB damage responses.

Histone ubiquitination has been implicated in several steps of DSB repair (Bao, 2011; Nakamura et al., 2011). H2AX ubiquitination at K119 is induced upon IR treatment in mammalian cells (Xie et al., 2010). Histone H2A/H2AX ubiquitination by RNF8 and RNF168 is also required for accumulation and retention of 53BP1 and BRCA1 at the DSB site (Huen et al., 2007; Kolas et al., 2007; Mailand et al., 2007; Doil et al., 2009). H2B ubiquitination can also contribute to DSB damage responses in mammals. We previously identified RNF20 as a novel human NBS1 binding partner through yeast two-hybrid analysis (Nakamura et al., 2011). RNF20, which can ubiquitinate $\mathrm{H} 2 \mathrm{~B}$ at $\mathrm{K} 119$, formed nuclear foci following IR and its accumulation at the DSB site was observed by I-SceI/ChIP analysis. siRNA-mediated depletion of RNF20 decreased the ubiquitination of histone H2B and enhanced sensitivity to IR and mitomycin $\mathrm{C}$ treatment. RNF20-deficient cells also showed a reduction in HRrelated focus formation such as BRCA1 and RAD51 foci, and reduced HR activity. Substituted H2B (K119A)overexpressing HeLa cells also displayed reduced formation of foci and reduced HR activity. Furthermore, IRinduced RPA focus formation, which is likely to be CtIPdependent, was also attenuated in RNF20-depleted cells and in mutated NBS1-expressing cells at RNF20-binding sites, suggesting that the interaction between NBS1 and RNF20 participates in the regulation of DSB end-resection through DSB-induced chromatin remodeling. On the other hand, we also found SUPT16H, a subunit of the FACT complex, to be an RNF20-binding partner (Oliveira et al., 2014). SUPT16H directly interacts with the Cterminal RING domain of RNF20. Depletion of SUPT16H caused similar defects to those observed in RNF20deficient cells regarding chromatin accumulation of RNF20, IR-induced focus formation of HR-related factors (BRCA1 and RAD51) and HR activity, suggesting that SUPT16H plays a key role in RNF20-dependent DDRs through its interactions. Depletion of SIRT6, a histone deacetylase, reduced RNF20 recruitment to DSB sites and also H2B K120 ubiquitination (Toiber et al., 2013; Vidi et al., 2014). Accumulation of RNF20 may be regulated by its histone acetylation status as well as its interaction with NBS1 and SNF2h. As mentioned above, NBS1 is a key regulator for ATM activation upon DSB damage, and NBS1-deficient cells show many aberrations in ATM-related responses, including $\mathrm{H} 2 \mathrm{AX}$ phosphorylation. $\mathrm{H} 2 \mathrm{~A} / \mathrm{H} 2 \mathrm{AX}$ ubiquitination by $\mathrm{RNF} 8 / \mathrm{RNF} 168$ is regulated in a $\gamma$-H2AX/MDC1-dependent manner. These observations suggest that NBS1 might function in DDRs through modifications such as $\mathrm{H} 2 \mathrm{AX}$ phosphorylation and $\mathrm{H} 2 \mathrm{~A} / \mathrm{H} 2 \mathrm{AX}$ ubiquitination, as well as RNF20-dependent H2B ubiquitination. 
The role of chromatin remodeling in $\mathrm{HR}$ repair, and its relationship with NBS1 Chromatin's structure facilitates the maintenance of genetic information within genomic DNA, but needs to be remodeled for various ends; this is carried out through the specific activity of histone modifiers, and through the roles of histone chaperones and ATP-dependent chromatin remodelers in DNA-related responses including transcription, replication and DNA repair. Predominantly, histone-modifying enzymes covalently modify the $\mathrm{N}$-terminal tails of histone proteins. This in turn may lead to the modulation of nucleosome dynamics by altering histone-DNA contacts or by altering the chromatin association of proteins that act on DNA or mediate signaling responses (Giglia-Mari et al., 2011). Furthermore, ATP-dependent chromatin remodeling complexes catalyze the disruption of DNAhistone contacts and can slide or evict nucleosomes using the energy from ATP hydrolysis in cooperation with histone chaperones, by exchanging histones and histone variants (Clapier and Cairns, 2009). So far, four structurally related and evolutionarily conserved families, SWI/SNF, INO80, CHD and ISWI, have been reported to act as chromatin remodeling complexes for transcription and DNA replication (Clapier and Cairns, 2009; Aydin et al., 2014). In the case of DSB damage responses, the interaction between $\gamma$-H2A and histone remodelers in yeast was the first to be reported. Yeast INO80 and SWR1 chromatin remodeling complexes interact with $\gamma$ H2A and facilitate DSB repair (van Attikum et al., 2007; Park et al., 2009). Wu and colleagues showed that knockdown models of human INO80, or of its binding partner YY1, increased cellular sensitivity toward DNAdamaging agents, and in their study they highlighted the essentiality of both INO80 and YY1 for HR repair (Wu, S. et al., 2007). However, a recent report indicated that H2A phosphorylation is dispensable for recruitment of the chromatin remodelers INO80 and SNF6 (a component of SWI/SNF) to DSB sites in yeast (Bennett et al., 2013), suggesting that the interaction with $\gamma-\mathrm{H} 2 \mathrm{AX}$ may not be essential for directing the accumulation of histone remodelers at DSB damage sites.

On the other hand, H2B ubiquitination may contribute to the recruitment of histone remodelers to DSB sites. We, as well as other groups, reported that the chromatin remodeling factor SNF2h/SMARCA5 is recruited to DSB damage sites induced by laser micro-irradiation (Nakamura et al., 2011; Toiber et al., 2013; Vidi et al., 2014). We also found that depletion of RNF20 reduced H2B ubiquitination-mediated methylation (H3-K4) and accumulation of SNF2h at DSB sites, suggesting that RNF20-dependent ubiquitination of H2B and H3 methylation are crucial for the recruitment of SNF2h to DSB sites. Depletion of SNF2h in human cells reduced IRinduced focus formation of HR factors, reduced HR activity, and enhanced the cells' sensitivity to IR and DNA- damaging agents such as mitomycin $\mathrm{C}$, suggesting that chromatin remodeling by SNF2h is important for HR repair. However, the recruitment and retention of SNF2h to DSB sites may require the involvement and actions of other factors. SNF2h can be recruited to DSB sites through its interaction with RNF168, poly-ADPribosylated by PARP1 (Smeenk et al., 2013). The structural nuclear protein NuMA may also contribute to SNF2h accumulation at DSB sites, and SIRT6 has been suggested to participate in the recruitment of SNF2h to chromatin containing DSB damage (Toiber et al., 2013; Vidi et al., 2014). SIRT6-depleted cells decrease SNF2h recruitment to DSB sites, but SIRT6-knockout mouse cells also decrease chromatin association of RNF20 and H2B ubiquitination (Toiber et al., 2013). Hence, the repression of chromatin association of SNF2h may be due to a reduction of RNF20 accumulation and subsequent H2B ubiquitination. Thus, SNF2h may function in DSB damage responses, primarily in HR repair following its recruitment to DSB sites by histone modification and through the involvement of other factors.

NBS1 may influence SNF2h-dependent chromatin remodeling through its interaction with RNF20, but it is also possible that NBS1 participates in an alternative chromatin remodeling pathway upon initiation of DSB damage responses. Several years ago, we identified the major nucleolar protein nucleolin as a novel binding partner of $\gamma$-H2AX (Kobayashi et al., 2012). As well as interacting with $\gamma$-H2AX, nucleolin also interacts with NBS1 following IR. Nucleolin-depleted cells abrogated HRrelated BRCA1, RAD51 and RPA focus formation, and subsequently reduced HR activity. RNF168 and H2A ubiquitination were also repressed in the depleted cells. Histone eviction is followed by chromatin remodeling during transcription and replication, and $\mathrm{H} 2 \mathrm{~B}$ eviction was induced in response to DSB damage in non-depleted cells. However, DSB damage-dependent eviction ceased in nucleolin-depleted cells, suggesting that nucleolin is important for histone eviction in response to DSB damage. Recently, Goldstein et al. (2013) reported that nucleolin could directly bind with the DNA repair protein RAD50, a component of the MRN complex, and this interaction contributed to the accumulation of RAD50 at DSB sites. Via ChIP analysis, this group also found that depletion of nucleolin disrupted the removal of H2A/H2B around DSB sites. Thus, nucleolin may be important for histone eviction from damaged nucleosomes and subsequent chromatin remodeling in response to DSB damage. NBS1 may also contribute to such DSB damage-triggered chromatin remodeling as a component of the MRN complex.

Chromatin modification and NHEJ repair NHEJ repair is initiated with recognition/binding of the KU70/ KU80/DNA-PKcs complex to DSB ends and finally com- 
pleted with rejoining of DSB ends by the XRCC4/Ligase IV complex (Fig. 2). As NHEJ is considered to require little or no end-resection, histone modification and chromatin remodeling are predicted to have less of a role in NHEJ repair than they have in HR repair. However, reports regarding the relationship between histone modification, including $\gamma$-H2AX, and NHEJ repair are limited. One of the factors involved in NHEJ repair, chromatinassociated factor 53BP1, can accumulate at DSB sites in a $\gamma$-H2AX-dependent manner, although H2AX-deficient cells show mild radiosensitivity and some end-joining when analyzed by comet assay (Scully and Xie, 2013). However, H2AX-knockout mice showed a mild defect in the re-joining of class switch recombination (CSR) (Franco et al., 2006). As most NHEJ factors, including 53BP1, participate in the CSR pathway, $\gamma$-H2AX may function in NHEJ repair through its interaction with 53BP1. As mentioned above, 53BP1 recognizes the methylation of H3-K79 and H4-K20, which then triggers its accumulation at DSB sites, and 53BP1 was recently reported to also recognize ubiquitination of H2A-K15 (Hartlerode et al., 2012; Wakeman et al., 2012; FradetTurcotte et al., 2013; Hsiao and Mizzen, 2013). Thus, such methylation and ubiquitination may have a role in NHEJ repair through 53BP1.

On the other hand, human NBS1, and conceivably also the MRN complex, has a limited role in NHEJ repair. As NBS patients frequently show chromosomal translocations at TCR loci, which are related to class switch recombination (Chen et al., 2000), a limited role for NBS1 or the MRN complex in the NHEJ pathway has been suggested. As mentioned above, the budding yeast NBS1 homolog Xrs2 binds to Lif1 (the yeast homolog of Ligase IV) through the FHA domain (Matsuzaki et al., 2012). Mutations in the FHA domain of Xrs2 decreased NHEJ repair efficiency, although they did not influence HR repair (Matsuzaki et al., 2012), suggesting that Xrs2 participates in the NHEJ pathway through interactions with Lif1. Recently, an alternative NHEJ (alt-NHEJ) pathway has been reported, and has also been termed MMEJ or single-strand annealing (SSA) repair. It was hypothesized that cells deficient in XRCC4, a factor involved in classical NHEJ, would use the alt-NHEJ pathway for DSB repair; however, depletion of MRE11 markedly decreased alt-NHEJ, suggesting a role of MRE11 in this alternative pathway, most likely when it is in the form of the MRN complex (Dinkelmann et al., 2009; Rass et al., 2009). DNA ligase III $\alpha$ and XRCC1 were also reported to be involved in the alt-NHEJ pathway (Della-Maria et al., 2011). The MRN complex has been confirmed to interact with the DNA ligase III $\alpha$ XRCC1 complex directly and to stimulate DNA ligase III $\alpha$ XRCC1-dependent intermolecular ligation in vitro, even for incompatible DNA ends, which mirrors alt-NHEJ repair, suggesting that NBS1 and likely the MRN complex participate in the alt-
NHEJ pathway. As mentioned above, NBS1 directly interacts with RNF20. RNF20 is indispensable for HR repair, but its depletion only mildly decreased NHEJ activity (Nakamura et al., 2011). As RNF20-depleted cells show normal focus formation of 53BP1 following IR, NBS1 may participate in NHEJ through RNF20-dependent ubiquitination of $\mathrm{H} 2 \mathrm{~B}$ in a 53BP1-independent manner.

The role of chromatin remodeling in NHEJ repair has been reported. A yeast strain deficient in the SWI/SNF family chromatin remodeling factor RSC showed no accumulation of YKU70/YKU80 complex or $\gamma$-H2A at DSB sites, although NHEJ is only a minor pathway of DSB repair in yeast (Kent et al., 2007; Shim et al., 2007). In the case of mammals, the recruitment of YKU70/YKU80 to DSB sites seems dependent on BAF, a component of the mammalian SWI/SNF complex (Watanabe et al., 2014). Moreover, depletion of PBAF1, another component of the SWI/SNF complex, decreased NHEJ activity (Kakarougkas et al., 2014). The results of these reports suggest that the SWI/SNF complex has a role in carrying out chromatin remodeling in the NHEJ pathway. SNF2h is known to form several types of complex, and several of the binding partners of these complexes have been reported to have a role in NHEJ as well as HR repair. The binding partners ACF and CHRAC directly interact with KU70, and depletion of ACF1 results in reduced accumulation of KU70 at DSB sites caused by laser microirradiation; ACF1 depletion also remarkably reduces NHEJ activity, whereas the reduction of NHEJ activity is only partial in SNF2h-depleted cells (Lan et al., 2010). The respective consequences of these depletions suggest that ACF1 functions in NHEJ through a distinct role from SNF2h.

Chromatin compaction is known to differ between euchromatin (EC) and heterochromatin (HC). As HC is more compacted than EC, HC presents a barrier to the progression of NHEJ. Both ATM-deficient and KAP1 (an ATM substrate)-depleted cells showed delayed kinetics for $\gamma$-H2AX foci in HC regions following IR, and ATMdependent phosphorylation of KAP1 at serine 824 seemed to be related to this phenomenon (Goodarzi et al., 2008). Artemis- or 53BP1-deficient cells also show a similar delay of $\gamma$-H2AX focus kinetics in the $\mathrm{HC}$ region, suggesting that NHEJ repair in HC regions may require ATMdependent phosphorylation of KAP1 (Riballo et al., 2004; Noon et al., 2010; Woodbine et al., 2011). KAP1 is usually sumoylated independently of DSB generation, and sumoylated KAP1 can interact with the chromatin remodeling factor CHD3. This interaction facilitates the compaction of HC. However, serine 824-phosphorylated KAP1 could not bind with CHD3, which caused a DSB damage-dependent release of CHD3 from $\mathrm{HC}$, leading to relaxation of HC for NHEJ repair (Goodarzi et al., 2008, 2010). NBS1-deficient patient cells also showed similar delayed kinetics of $\gamma$-H2AX foci in $\mathrm{HC}$ regions following 
IR, and the MRN complex accumulated at DSB regions in $\mathrm{HC}$ in a 53BP1-dependent manner, suggesting that NBS1 functions in NHEJ repair in an ATM-dependent and also -independent manner (Riballo et al., 2004; Noon et al., 2010). Thus, NBS1 may play a role in NHEJ in EC through RNF20-dependent ubiquitination of $\mathrm{H} 2 \mathrm{~B}$, and in HC through regulation of ATM kinase for KAP1 phosphorylation and interaction with 53BP1.

Relationship between chromatin modification and DNA damage associated with stalled replication forks Various types of DNA damage, induced by UV radiation, oxidative stress, DNA alkylation or other genome stress factors, can stall progression of DNA replication. Stalled replication forks are open to attack by endogenous nucleases and can lead to loss of genome stability; therefore, rapid repair of DNA damage on stalled forks is ideally carried out and then DNA replication restarts. However, if the damage is not repaired or is bypassed, or if a single-strand break is incorporated into the template, the stalled fork can collapse, leading to a DSB. Stalling of DNA replication can induce activation of ATR (Nam and Cortez, 2011). ATR is a member of the ATM family of kinases, and activated ATR phosphorylates various substrates at SQ/TQ motifs, with the result that cell cycle checkpoints are activated. ATRIP protein, a critical interaction partner for ATR, mediates the accumulation of ATR on damaged chromatin via its interaction with the RPA complex, which recognizes and coats ssDNA generated on stalled forks (Zou and Elledge, 2003). In parallel, TopBP1 is recruited by the RAD9RAD1-HUS1 (9-1-1) checkpoint clamp, which is loaded onto DNA by the RAD17-replication factor C clamp loader complex (Nam and Cortez, 2011). These actions result in the catalytic activation of ATR through direct binding of the ATR-ATRIP complex to the activation domain of TopBP1 (Nam and Cortez, 2011). ATR-deficient Seckel syndrome is reported to have certain phenotypes in common with NBS, such as microcephaly and abnormal regulation of centrosome replication (Shimada et al., 2009; Nam and Cortez, 2011). NBS patient cells also show significant decreases in the ATR-related phosphorylation of proteins such as Chk1 and p53 following hydroxyurea treatment, and fail to restart stalled replication (Stiff et al., 2005; Jazayeri et al., 2006). Moreover, we observed that the interaction of TopBP1 with the $\mathrm{N}$ terminus of NBS1 is important for the recruitment of TopBP1 to DNA damage sites (Morishima et al., 2007). Recently, it was reported that NBS1 is crucial for secondary ATRdependent phosphorylation such as that of RPA. Shiotani et al. (2013) showed that depletion of NBS1 remarkably decreased RPA phosphorylation at serine 33 after camptothecin treatment. Interaction between NBS1 and RPA32 was also reported to be via the C-terminal domain (a.a. 549-561) of NBS1. Taken together, this informa- tion leads to the conclusion that NBS1 contributes to ATR activation through its interactions with RPA32 and TopBP1.

As a stalled fork can cause DSBs, $\gamma$-H2AX (or $\gamma$-H2A in yeast) is also induced at stalled forks. This phosphorylation is carried out by ATR (MEC1 in budding yeast). Genome-wide mapping of $\gamma$-H2A-rich loci using ChIP analysis clarified that $\gamma \mathrm{H} 2 \mathrm{~A}$ accumulates at the sites of naturally stalled forks, including the ribosomal DNA locus, tRNA genes, telomeres and DNA replication origins in Saccharomyces cerevisiae (Szilard et al., 2010). The average size of the $\gamma$-H2A domain at these natural stall sites was $1255 \mathrm{bp}$, while HO endonuclease-induced DSBs caused accumulations of $\gamma-\mathrm{H} 2 \mathrm{~A}$ each spanning around 50 $\mathrm{kb}$ at DSB sites in $S$. cerevisiae, suggesting that $\gamma-\mathrm{H} 2 \mathrm{AX} /$ $\gamma$-H2A at stalled forks has a different role to that of $\gamma$ $\mathrm{H} 2 \mathrm{AX} / \gamma-\mathrm{H} 2 \mathrm{~A}$ at DSB sites that have been induced by IR. H2AX-depleted human cells showed mild sensitivity to camptothecin (Furuta et al., 2003); however, the detailed role of $\mathrm{H} 2 \mathrm{AX}$ phosphorylation in maintenance of a stalled fork remains unclear.

The relationship between replication fork stalls and other histone modifications has also been investigated. In human T-cell lymphoma cells, HDAC3 accumulates around replication forks in a manner that shows a link between acetylation state and newly synthesized DNA; HDAC3 inhibition resulted in repression of replication fork progression and induced apoptosis with increased $\gamma$ H2AX and an S-phase defect (Wells et al., 2013). In the case of H3-K56 of yeast, acetylation is required to complete replication in the presence of lesions caused by methylmethane sulfonate (MMS) (Wurtele et al., 2012), and yeast cells defective in both CLR4 and SET2 (methyltransferases for $\mathrm{H} 3-\mathrm{K} 9$ and $\mathrm{H} 3-\mathrm{K} 36$, respectively) showed decreased RAD3 (fission yeast homolog of ATR)dependent phosphorylation of CDC2 and MIK1 following hydroxyurea treatment, suggesting that hydroxyureainduced replication stress checkpoints require $\mathrm{H} 3$ methylation by CLR4 and SET2 (Kim et al., 2008). Furthermore, H3-K4 trimethylation may also contribute to repair of Sphase damage in $S$. cerevisiae, as the absence of SET1, a $\mathrm{HMT}$ responsible for $\mathrm{H} 3-\mathrm{K} 4$ trimethylation, leads to an $\mathrm{S}$ phase progression defect (Faucher and Wellinger, 2010). Thus, histone modifications such as phosphorylation, acetylation and methylation may play a role in fork stall-related damage responses.

Chromatin remodeling, as well as histone modification, may participate in DDRs at a stalled replication fork. INO80 is implicated in recovery from stalled replication in both budding yeast and mammalian cells. INO80deficient mammalian cells show sensitivity to hydroxyurea, and are defective in both S-phase progression and recovery from replication stress (Hur et al., 2010; Min et al., 2013; Vassileva et al., 2014). Enrichment of INO80 at stalled replication forks has been detected in yeast by 
ChIP analysis (Papamichos-Chronakis and Peterson, 2008; Shimada et al., 2008). Furthermore, yeast lacking in functions of both INO80 and ISW2 cannot recover from the S-phase checkpoint (Au et al., 2011). Moreover, accumulation of the chromatin remodeler RSC2 near replication forks has been detected by ChIP analysis, and PCNA ubiquitination, induced by stalling of replication forks, significantly decreased in an RSC2 mutant after UV and hydroxyurea treatment in yeast (Niimi et al., 2012). In the case of mammalian cells, depletion of BAF180 (functionally similar to yeast RSC2) led to a decrease in fork progression and chromatin association of both PCNA and RAD18 (Niimi et al., 2012). Thus, chromatin remodeling as well as histone modification may have a role in DDRs at stalled replication forks. However, Niimi et al.'s experimental inactivation of histone modification or chromatin remodeling factors may repress replication fork progression, leading to stalling; in this regard, further research is required to establish whether such chromatin modification is important for replication or maintenance/restart of stalled forks. Although NBS1 has been shown or implied to play some role in the activation of ATR in response to replication fork stalling, its relationship with chromatin modification remains unclear.

Concluding remarks Genomic DNA is packaged into chromatin via nucleosome units containing histone octamers. This structure can stably maintain gene information even against various stresses including IR, UV radiation and ROS. However, once DNA damage is induced by such stressors, chromatin's stable structure has to be reorganized to facilitate DDRs such as DNA repair. Based on the findings of many published reports regarding transcription regulation and replication, such reorganization is likely to be promoted through histone modification and cooperative chromatin remodeling via various factors related to the DDRs (Tables 1 and 2, Fig. 2 ). Over more than 15 years, it has been proven that phosphorylation of $\mathrm{H} 2 \mathrm{AX}$ (to $\gamma$-H2AX) is important for DSB damage responses such as the accumulation of DDR proteins and subsequent activation of the $\mathrm{HR}$ repair pathway. Furthermore, other histone modifications such as acetylation, methylation and ubiquitination are now thought to be indispensable in the progression of DDRs. As described above, mammalian NBS1 is a multi-functional protein active in various DDRs. Its recently identified binding partner RNF20 is an E3 ubiquitin ligase for histone $\mathrm{H} 2 \mathrm{~B}$ and its ubiquitinating action is crucial for the recruitment of $\mathrm{SNF} 2 \mathrm{~h}$, a chromatin remodeler, to DSB damage sites. Accumulated reports indicate that SNF2h functions in HR repair, probably through the regulation of end-resection. NBS1 also

Table 1. Relationships between histone modifications and DDR pathways

\begin{tabular}{|c|c|c|c|c|}
\hline Modification & Enzyme & System & DDR pathway & Reference \\
\hline \multicolumn{5}{|c|}{ Phosphorylation } \\
\hline \multirow[t]{2}{*}{$\gamma$-H2AX } & ATM & Mammal & HR, cell cycle & Kobayashi et al. (2009), Aydin et al. (2014) \\
\hline & (ATR, DNA-PK) & & checkpoint & \\
\hline$\gamma-\mathrm{H} 2 \mathrm{~A}$ & $\operatorname{Rad} 3$, Tel1 & Yeast & Stalled replication & Szilard et al. (2010) \\
\hline \multicolumn{5}{|l|}{ Acetylation } \\
\hline $\mathrm{H} 2 \mathrm{~A}$ & TIP60 & Mammal & HR & Kobayashi et al. (2010) \\
\hline $\mathrm{H} 3, \mathrm{H} 4$ & Arp4 & Yeast & HR & Tamburini and Tyler (2005) \\
\hline H4-K16 & MOF & Mammal & Repair choice & Li et al. (2010), Krishnan et al. (2011), Gupta et al. (2014) \\
\hline H3-K36 & GCN5 & Yeast & HR & Pai et al. (2014) \\
\hline H3-K56 & $?$ & Yeast & Stalled replication & Wurtele et al. (2012) \\
\hline \multicolumn{5}{|l|}{ Methylation } \\
\hline $\mathrm{H} 4-\mathrm{K} 20$ & SET8 & Mammal & NHEJ (through 53BP1) & Dulev et al. (2014) \\
\hline H3-K36 & SETD2 & Mammal & HR (through CtIP) & Pfister et al. (2014) \\
\hline \multirow[t]{2}{*}{ H3-K36 } & SET2 & Yeast & NHEJ & Pai et al. (2014) \\
\hline & SET2 & Yeast & Stalled replication & Kim et al. (2008) \\
\hline H3-K9 & CLR4 & Yeast & Stalled replication & Kim et al. (2008) \\
\hline H3-K4 & SET1 & Yeast & Stalled replication & Faucher and Wellinger (2010) \\
\hline H2AX-K134 & SUV39H2 & Mammal & DNA repair & Sone et al. (2014) \\
\hline \multicolumn{5}{|l|}{ Ubiquitination } \\
\hline $\mathrm{H} 2 \mathrm{~A}(\mathrm{X})$ & RNF8, RNF168 & Mammal & HR & Huen et al. (2007), Kolas et al. (2007), Mailand et al. (2007) \\
\hline H2B-K119 & RNF20 & Mammal & HR & Nakamura et al. (2011), Bao (2011) \\
\hline
\end{tabular}


Table 2. Relationships between chromatin remodelers and DDR pathways

\begin{tabular}{llll}
\hline \hline Chromatin remodeler & System & \multicolumn{1}{c}{ DDR pathway } & \multicolumn{1}{c}{ Reference } \\
\hline INO80 & Yeast & DNA repair (HR?) & van Attikum et al. (2007), Park et al. (2009) \\
& Yeast & Stalled replication & $\begin{array}{l}\text { Papamichos-Chronakis and Peterson (2008), Shimada et al. (2008), } \\
\text { Au et al. (2011) }\end{array}$ \\
& Mammal & Stalled replication & Hur et al. (2010), Min et al. (2013), Vassileva et al. (2014) \\
INO80/YY1 complex & Mammal & HR & Wu, S. et al. (2007) \\
SWR1 & Yeast & DNA repair (HR?) & van Attikum et al. (2007) \\
ISW2 & Yeast & Stalled replication & Au et al. (2011) \\
SNF2h & Mammal & HR repair & Nakamura et al. (2011) \\
Nucleolin & Mammal & HR, cell cycle checkpoint & Kobayashi et al. (2012) \\
RSC & Yeast & NHEJ & Kent et al. (2007), Shim et al. (2007) \\
RSC2 & Yeast & Stalled replication & Niimi et al. (2012) \\
BAF & Mammal & NHEJ & Watanabe et al. (2014) \\
PBAF1 & Mammal & NHEJ & Kakarougkas et al. (2014) \\
BAF180 & Mammal & Stalled replication & Niimi et al. (2012) \\
ACF1 & Mammal & NHEJ (through KU) & Lan et al. (2010) \\
CHRAC & Mammal & NHEJ (through KU) & Lan et al. (2010) \\
CHD3 & Mammal & NHEJ (through KAP1) & Goodarzi et al. (2008, 2010) \\
\hline
\end{tabular}

interacts with nucleolin, likely via an interaction with $\gamma$ H2AX. Nucleolin seems to function in the eviction of H2A/H2B from damaged nucleosomes, and subsequently facilitates HR repair. Moreover, as NBS1 is an essential factor for ATM activation through their direct interaction, and ATM is important for KAP1/CHD3-dependent chromatin remodeling in $\mathrm{HC}$ regions to facilitate $\mathrm{DSB}$ repair, NBS1 may also participate in this KAP1/CHD3-dependent chromatin remodeling. Therefore, NBS1 may function in histone modification and in the coordination of chromatin remodeling to promote efficient and effective DSB repair. A major DDR protein, NBS1 contributes to HR-related histone modification and chromatin remodeling with the histone modification enzyme RNF20, but it is unclear whether other DDR proteins display physical or functional interactions with histone modification enzymes or chromatin remodelers in DDRs. These interactions will have to be clarified by further studies.

We thank Drs. Kenshi Komatsu, Hiroshi Tauchi, Shinya Matsuura, Akihiro Kato, Hiromi Yanagihara, Kyosuke Nakamura and Mikio Shimada for their critical comments on the manuscript. We also thank Yukiko Hayuka and Kae Yanagida for their technical contributions, and Michi Tanizaki for the preparation of the manuscript. This work was supported in part by grants (Nos. 18101002, 24310041 and 25550026) from the Ministry of Education, Culture, Sports, Science and Technology, and by a Health and Labor Science Research Grant.

\section{REFERENCES}

Ataian, Y., and Krebs, J. E. (2006) Five repair pathways in one context: chromatin modification during DNA repair. Biochem. Cell Biol. 84, 490-504.

Au, T. J., Rodriguez, J., Vincent, J. A., and Tsukiyama, T. (2011) ATP-dependent chromatin remodeling factors tune $\mathrm{S}$ phase checkpoint activity. Mol. Cell. Biol. 31, 4454-4463.

Aydin, Ö. Z., Vermeulen, W., and Lans, H. (2014) ISWI chromatin remodeling complexes in the DNA damage response. Cell Cycle 13, 3016-3025.

Bakkenist, C. J., and Kastan, M. B. (2003) DNA damage activates ATM through intermolecular autophosphorylation and dimer dissociation. Nature 421, 499-506.

Bao, Y. (2011) Chromatin response to DNA double-strand break damage. Epigenomics 3, 307-321.

Bennett, G., Papamichos-Chronakis, M., and Peterson, C. L. (2013) DNA repair choice defines a common pathway for recruitment of chromatin regulators. Nat. Commun. 4, 2084.

Chailleux, C., Tyteca, S., Papin, C., Boudsocq, F., Puget, N., Courilleau, C., Grigoriev, M., Canitrot, Y., and Trouche, D. (2010) Physical interaction between the histone acetyl transferase Tip60 and the DNA double-strand breaks sensor MRN complex. Biochem. J. 426, 365-371.

Chapman, J. R., and Jackson, S. P. (2008) Phospho-dependent interactions between NBS1 and MDC1 mediate chromatin retention of the MRN complex at sites of DNA damage. EMBO Rep. 9, 795-801.

Chen, H. T., Bhandoola, A., Difilippantonio, M. J., Zhu, J., Brown, M. J., Tai, X., Rogakou, E. P., Brotz, T. M., Bonner, W. M., Ried, T., et al. (2000) Response to RAG-mediated V(D)J cleavage by NBS1 and $\gamma$-H2AX. Science 290, 19621964

Clapier, C. R., and Cairns, B. R. (2009) The biology of chromatin remodeling complexes. Annu. Rev. Biochem. 78, 273-304.

Della-Maria, J., Zhou, Y., Tsai, M. S., Kuhnlein, J., Carney, J. 
P., Paull, T. T., and Tomkinson, A. E. (2011) Human Mre11/ human Rad50/Nbs1 and DNA ligase III $\alpha /$ XRCC1 protein complexes act together in an alternative nonhomologous end joining pathway. J. Biol. Chem. 286, 33845-33853.

Dinkelmann, M., Spehalski, E., Stoneham, T., Buis, J., Wu, Y., Sekiguchi, J. M., and Ferguson, D. O. (2009) Multiple functions of MRN in end-joining pathways during isotype class switching. Nat. Struct. Mol. Biol. 16, 808-813.

Dodson, G. E., Limbo, O., Nieto, D., and Russell, P. (2010) Phosphorylation-regulated binding of Ctp1 to Nbs1 is critical for repair of DNA double-strand breaks. Cell Cycle 9, 15161522.

Doil, C., Mailand, N., Bekker-Jensen, S., Menard, P., Larsen, D. H., Pepperkok, R., Ellenberg, J., Panier, S., Durocher, D., Bartek, J., et al. (2009) RNF168 binds and amplifies ubiquitin conjugates on damaged chromosomes to allow accumulation of repair proteins. Cell 136, 435-446.

Downs, J. A., Allard, S., Jobin-Robitaille, O., Javaheri, A., Auger, A., Bouchard, N., Kron, S. J., Jackson, S. P., and Côté, J. (2004) Binding of chromatin-modifying activities to phosphorylated histone H2A at DNA damage sites. Mol. Cell 16, 979-990.

Dulev, S., Tkach, J., Lin, S., and Batada, N. N. (2014) SET8 methyltransferase activity during the DNA double-strand break response is required for recruitment of 53BP1. EMBO Rep. 15, 1163-1174.

Durocher, D., Henckel, J., Fersht, A. R., and Jackson, S. P. (1999) The FHA domain is a modular phosphopeptide recognition motif. Mol. Cell 4, 387-394.

Ehrenhofer-Murray, A. E. (2004) Chromatin dynamics at DNA replication, transcription and repair. Eur. J. Biochem. 271, 2335-2349.

Faucher, D., and Wellinger, R. J. (2010) Methylated H3K4, a transcription-associated histone modification, is involved in the DNA damage response pathway. PLoS Genet. 6, e1001082.

Fradet-Turcotte, A., Canny, M. D., Escribano-Díaz, C., Orthwein, A., Leung, C. C., Huang, H., Landry, M. C., Kitevski-LeBlanc, J., Noordermeer, S. M., Sicheri, F., et al. (2013) 53BP1 is a reader of the DNA-damage-induced H2A Lys 15 ubiquitin mark. Nature 499, 50-54.

Franco, S., Gostissa, M., Zha, S., Lombard, D. B., Murphy, M. M., Zarrin, A. A., Yan, C., Tepsuporn, S., Morales, J. C., Adams, M. M., et al. (2006) H2AX prevents DNA breaks from progressing to chromosome breaks and translocations. Mol. Cell 21, 201-214.

Furuta, T., Takemura, H., Liao, Z. Y., Aune, G. J., Redon, C., Sedelnikova, O. A., Pilch, D. R., Rogakou, E. P., Celeste, A., Chen, H. T., et al. (2003) Phosphorylation of histone H2AX and activation of Mre11, Rad50, and Nbs1 in response to replication-dependent DNA double-strand breaks induced by mammalian DNA topoisomerase I cleavage complexes. J. Biol. Chem. 278, 20303-20312.

Giglia-Mari, G., Zotter, A., and Vermeulen, W. (2011) DNA damage response. Cold Spring Harb. Perspect. Biol. 3, a000745.

Goldstein, M., Derheimer, F. A., Tait-Mulder, J., and Kastan, M. B. (2013) Nucleolin mediates nucleosome disruption critical for DNA double-strand break repair. Proc. Natl. Acad. Sci. USA 110, 16874-16879.

Goodarzi, A. A., Noon, A. T., Deckbar, D., Ziv, Y., Shiloh, Y., Löbrich, M., and Jeggo, P. A. (2008) ATM signaling facilitates repair of DNA double-strand breaks associated with heterochromatin. Mol. Cell 31, 167-177.

Goodarzi, A. A., Jeggo, P., and Lobrich, M. (2010) The influence of heterochromatin on DNA double strand break repair: get- ting the strong, silent type to relax. DNA Repair 9, 12731282.

Gottlieb, T. M., and Jackson, S. P. (1993) The DNA-dependent protein kinase: requirement for DNA ends and association with $\mathrm{Ku}$ antigen. Cell 72, 131-142.

Gupta, A., Hunt, C. R., Hegde, M. L., Chakraborty, S., Udayakumar, D., Horikoshi, N., Singh, M., Ramnarain, D. B., Hittelman, W. N., Namjoshi, S., et al. (2014) MOF phosphorylation by ATM regulates 53BP1-mediated doublestrand break repair pathway choice. Cell Rep. 8, 177-189.

Hartlerode, A. J., Guan, Y., Rajendran, A., Ura, K., Schotta, G., Xie, A., Shah, J. V., and Scully, R. (2012) Impact of histone $\mathrm{H} 4$ lysine 20 methylation on 53BP1 responses to chromosomal double strand breaks. PLoS ONE 7, e49211.

House, N. C., Koch, M. R., and Freudenreich, C. H. (2014) Chromatin modifications and DNA repair: beyond double-strand breaks. Front. Genet. 5, 296.

Hsiao, K. Y., and Mizzen, C. A. (2013) Histone H4 deacetylation facilitates 53BP1 DNA damage signaling and double-strand break repair. J. Mol. Cell Biol. 5, 157-165.

Huen, M. S., Grant, R., Manke, I., Minn, K., Yu, X., Yaffe, M. B., and Chen, J. (2007) RNF8 transduces the DNA-damage signal via histone ubiquitylation and checkpoint protein assembly. Cell 131, 901-914.

Hur, S. K., Park, E. J., Han, J. E., Kim, Y. A., Kim, J. D., Kang, D., and Kwon, J. (2010) Roles of human INO80 chromatin remodeling enzyme in DNA replication and chromosome segregation suppress genome instability. Cell. Mol. Life Sci. 67, 2283-2296.

Ikura, T., Ogryzko, V. V., Grigoriev, M., Groisman, R., Wang, J., Horikoshi, M., Scully, R., Qin, J., and Nakatani, Y. (2000) Involvement of the TIP60 histone acetylase complex in DNA repair and apoptosis. Cell 102, 463-473.

Ikura, T., Tashiro, S., Kakino, A., Shima, H., Jacob, N., Amunugama, R., Yoder, K., Izumi, S., Kuraoka, I., Tanaka, K., et al. (2007) DNA damage-dependent acetylation and ubiquitination of $\mathrm{H} 2 \mathrm{AX}$ enhances chromatin dynamics. Mol. Cell. Biol. 27, 7028-7040.

Jazayeri, A., Falck, J., Lukas, C., Bartek, J., Smith, G. C., Lukas, J., and Jackson, S. P. (2006) ATM- and cell cycledependent regulation of ATR in response to DNA doublestrand breaks. Nat. Cell Biol. 8, 37-45.

Kakarougkas, A., Ismail, A., Chambers, A. L., Riballo, E., Herbert, A. D., Künzel, J., Löbrich, M., Jeggo, P. A., and Downs, J. A. (2014) Requirement for PBAF in transcriptional repression and repair at DNA breaks in actively transcribed regions of chromatin. Mol. Cell 55, 723-732.

Kent, N. A., Chambers, A. L., and Downs, J. A. (2007) Dual chromatin remodeling roles for RSC during DNA double strand break induction and repair at the yeast MAT locus. J. Biol. Chem. 282, 27693- 27701.

Kim, H. S., Rhee, D. K., and Jang, Y. K. (2008) Methylations of histone H3 lysine 9 and lysine 36 are functionally linked to DNA replication checkpoint control in fission yeast. Biochem. Biophys. Res. Commun. 368, 419-425.

Kobayashi, J., Tauchi, H., Sakamoto, S., Nakamura, A., Morishima, K., Matsuura, S., Kobayashi, T., Tamai, K., Tanimoto, K., and Komatsu, K. (2002) NBS1 localizes to $\gamma$ $\mathrm{H} 2 \mathrm{AX}$ foci through interaction with the FHA/BRCT domain. Curr. Biol. 12, 1846-1851.

Kobayashi, J., Antoccia, A., Tauchi, H., Matsuura, S., and Komatsu, K. (2004) NBS1 and its functional role in the DNA damage response. DNA Repair 3, 855-861.

Kobayashi, J., Tauchi, H., Chen, B., Burma, S., Tashiro, S., Matsuura, S., Tanimoto, K., Chen, D. J., and Komatsu, K. 
(2009) Histone H2AX participates the DNA damage-induced ATM activation through interaction with NBS1. Biochem. Biophys. Res. Commun. 380, 752-757.

Kobayashi, J., Kato, A., Ota, Y., Ohba, R., and Komatsu, K. (2010) Bisbenzamidine derivative, pentamidine represses DNA damage response through inhibition of histone H2A acetylation. Mol. Cancer 9, 34 .

Kobayashi, J., Fujimoto, H., Sato, J., Hayashi, I., Burma, S., Matsuura, S., Chen, D. J., and Komatsu, K. (2012) Nucleolin participates in DNA double-strand break-induced damage response through MDC1-dependent pathway. PLoS ONE 7, e49245.

Kolas, N. K., Chapman, J. R., Nakada, S., Ylanko, J., Chahwan, R., Sweeney, F. D., Panier, S., Mendez, M., Wildenhain, J., Thomson, T. M., et al. (2007) Orchestration of the DNAdamage response by the RNF8 ubiquitin ligase. Science 318, 1637-1640.

Krishnan, V., Chow, M. Z., Wang, Z., Zhang, L., Liu, B., Liu, X., and Zhou, Z. (2011) Histone H4 lysine 16 hypoacetylation is associated with defective DNA repair and premature senescence in Zmpste24-deficient mice. Proc. Natl. Acad. Sci. USA 108, 12325-12330.

Lan, L., Ui, A., Nakajima, S., Hatakeyama, K., Hoshi, M., Watanabe, R., Janicki, S. M., Ogiwara, H., Kohno, T., Kanno, S., and Yasui, A. (2010) The ACF1 complex is required for DNA double- strand break repair in human cells. Mol. Cell 40, 976-987.

Lee, K. Y., and Myung, K. (2008) PCNA modifications for regulation of post-replication repair pathways. Mol. Cells 26, $5-11$.

Li, X., Corsa, C. A., Pan, P. W., Wu, L., Ferguson, D., Yu, X., Min, J., and Dou, Y. (2010) MOF and H4 K16 acetylation play important roles in DNA damage repair by modulating recruitment of DNA damage repair protein Mdc1. Mol. Cell. Biol. 30, 5335-5347.

Lim, D. S., Kim, S. T., Xu, B., Maser, R. S., Lin, J., Petrini, J. H., and Kastan, M. B. (2000) ATM phosphorylates p95/nbs1 in a S-phase checkpoint pathway. Nature 404, 613-617.

Lou, Z., Minter-Dykhouse, K., Franco, S., Gostissa, M., Rivera, M. A., Celeste, A., Manis, J. P., van Deursen, J., Nussenzweig, A., Paull, T. T., et al. (2006) MDC1 maintains genomic stability by participating in the amplification of ATM-dependent DNA damage signals. Mol. Cell 21, 187-200.

Mahaney, B. L., Meek, K., and Lees-Miller, S. P. (2009) Repair of ionizing radiation- induced DNA double-strand breaks by non-homologous end-joining. Biochem. J. 417, 639-650.

Mailand, N., Bekker-Jensen, S., Faustrup, H., Melander, F., Bartek, J., Lukas, C., and Lukas, J. (2007) RNF8 ubiquitylates histones at DNA double-strand breaks and promotes assembly of repair proteins. Cell 131, 887-900.

Masutani, C., Kusumoto, R., Iwai, S., and Hanaoka, F. (2000) Mechanisms of accurate translesion synthesis by human DNA polymerase $\eta$. EMBO J. 19, 3100-3109.

Matsuzaki, K., Terasawa, M., Iwasaki, D., Higashide, M., and Shinohara, M. (2012) Cyclin-dependent kinase-dependent phosphorylation of Lif1 and Sae2 controls imprecise nonhomologous end joining accompanied by double-strand break resection. Genes Cells 17, 473-493.

McGhee, J. D., and Felsenfeld, G. (1980) Nucleosome structure. Annu. Rev. Biochem. 49, 1115-1156.

Melander, F., Bekker-Jensen, S., Falck, J., Bartek, J., Mailand, N., and Lukas, J. (2008) Phosphorylation of SDT repeats in the MDC1 $\mathrm{N}$ terminus triggers retention of NBS1 at the DNA damage-modified chromatin. J. Cell Biol. 181, 213226.
Mimitou, E. P., and Symington, L. S. (2011) DNA end resectionunraveling the tail. DNA Repair 10, 344-348.

Min, J. N., Tian, Y., Xiao, Y., Wu, L., Li, L., and Chang, S. (2013) The mINO80 chromatin remodeling complex is required for efficient telomere replication and maintenance of genome stability. Cell Res. 23, 1396-1413.

Morishima, K., Sakamoto, S., Kobayashi, J., Izumi, H., Suda, T., Matsumoto, Y., Tauchi, H., Ide, H., Komatsu, K., and Matsuura, S. (2007) TopBP1 associates with NBS1 and is involved in homologous recombination repair. Biochem. Biophys. Res. Commun. 362, 872-879.

Nakamura, K., Kato, A., Kobayashi, J., Yanagihara, H., Sakamoto, S., Oliveira, D. V., Shimada, M., Tauchi, H., Suzuki, H., Tashiro, S., et al. (2011) Regulation of homologous recombination by RNF20-dependent H2B ubiquitination. Mol. Cell 41, 515-528.

Nam, E. A., and Cortez, D. (2011) ATR signalling: more than meeting at the fork. Biochem. J. 436, 527-536.

Niimi, A., Chambers, A. L., Downs, J. A., and Lehmann, A. R. (2012) A role for chromatin remodellers in replication of damaged DNA. Nucleic Acids Res. 40, 7393-7403.

Noon, A. T., Shibata, A., Rief, N., Löbrich, M., Stewart, G. S., Jeggo, P. A., and Goodarzi, A. A. (2010) 53BP1-dependent robust localized KAP-1 phosphorylation is essential for heterochromatic DNA double-strand break repair. Nat. Cell Biol. 12, 177-184.

O'Driscoll, M., and Jeggo, P. A. (2006) The role of double-strand break repair - insights from human genetics. Nat. Rev. Genet. 7, 45-54.

Oliveira, D. V., Kato, A., Nakamura, K., Ikura, T., Okada, M., Kobayashi, J., Yanagihara, H., Saito, Y., Tauchi, H., and Komatsu, K. (2014) Histone chaperone FACT regulates homologous recombination by chromatin remodeling through interaction with RNF20. J. Cell Sci. 127, 763-772.

Pai, C. C., Deegan, R. S., Subramanian, L., Gal, C., Sarkar, S., Blaikley, E. J., Walker, C., Hulme, L., Bernhard, E., Codlin, S., et al. (2014) A histone H3K36 chromatin switch coordinates DNA double-strand break repair pathway choice. Nat. Commun. 5, 4091.

Papamichos-Chronakis, M., and Peterson, C. L. (2008) The Ino80 chromatin-remodeling enzyme regulates replisome function and stability. Nat. Struct. Mol. Biol. 15, 338-345.

Park, J. H., Park, E. J., Hur, S. K., Kim, S., and Kwon, J. (2009) Mammalian SWI/SNF chromatin remodeling complexes are required to prevent apoptosis after DNA damage. DNA Repair 8, 29-39.

Pfister, S. X., Ahrabi, S., Zalmas, L. P., Sarkar, S., Aymard, F., Bachrati, C. Z., Helleday, T., Legube, G., La Thangue, N. B., Porter, A. C., et al. (2014) SETD2-dependent histone H3K36 trimethylation is required for homologous recombination repair and genome stability. Cell Rep. 7, 2006-2018.

Rass, E., Grabarz, A., Plo, I., Gautier, J., Bertrand, P., and Lopez, B. S. (2009) Role of Mre11 in chromosomal nonhomologous end joining in mammalian cells. Nat. Struct. Mol. Biol. 16, 819-824.

Rein, K., and Stracker, T. H. (2014) The MRE11 complex: an important source of stress relief. Exp. Cell Res. 329, 162169.

Riballo, E., Kühne, M., Rief, N., Doherty, A., Smith, G. C., Recio, M. J., Reis, C., Dahm, K., Fricke, A., Krempler, A., et al. (2004) A pathway of double-strand break rejoining dependent upon ATM, Artemis, and proteins locating to $\gamma$-H2AX foci. Mol. Cell 16, 715-724.

Rogakou, E. P., Pilch, D. R., Orr, A. H., Ivanova, V. S., and Bonner, W. M. (1998) DNA double-stranded breaks induce 
histone H2AX phosphorylation on serine 139. J. Biol. Chem. 273, 5858-5868.

Sakamoto, S., Iijima, K., Mochizuki, D., Nakamura, K., Teshigawara, K., Kobayashi, J., Matsuura, S., Tauchi, H., and Komatsu, K. (2007) Homologous recombination repair is regulated by domains at the $\mathrm{N}$ - and C-terminus of NBS1 and is dissociated with ATM functions. Oncogene 26, 6002-6009.

Scully, R., and Xie, A. (2013) Double strand break repair functions of histone H2AX. Mutat. Res. 750, 5-14.

Shibata, A., Moiani, D., Arvai, A. S., Perry, J., Harding, S. M., Genois, M. M., Maity, R., van Rossum-Fikkert, S., Kertokalio, A., Romoli, F., et al. (2014) DNA double-strand break repair pathway choice is directed by distinct MRE11 nuclease activities. Mol. Cell 53, 7-18.

Shiloh, Y. (1997) Ataxia-telangiectasia and the Nijmegen breakage syndrome: related disorders but genes apart. Annu. Rev. Genet. 31, 635-662.

Shim, E. Y., Hong, S. J., Oum, J. H., Yanez, Y., Zhang, Y., and Lee, S. E. (2007) RSC mobilizes nucleosomes to improve accessibility of repair machinery to the damaged chromatin. Mol. Cell. Biol. 27, 1602-1613.

Shimada, K., Oma, Y., Schleker, T., Kugou, K., Ohta, K., Harata, M., and Gasser, S. M. (2008) Ino80 chromatin remodeling complex promotes recovery of stalled replication forks. Curr. Biol. 18, 566-575.

Shimada, M., Sagae, R., Kobayashi, J., Habu, T., and Komatus, K. (2009) Inactivation of the Nijmegen breakage syndrome gene leads to excess centrosome duplication via the ATR/ BRCA1 pathway. Cancer Res. 69, 1768-1775.

Shiotani, B., Nguyen, H. D., Håkansson, P., Maréchal, A., Tse, A., Tahara, H., and Zou, L. (2013) Two distinct modes of ATR activation orchestrated by Rad17 and Nbs1. Cell Rep. 3, 1651-1662.

Smeenk, G., Wiegant, W. W., Marteijn, J. A., Luijsterburg, M. S., Sroczynski, N., Costelloe, T., Romeijn, R. J., Pastink, A., Mailand, N., Vermeulen, W., et al. (2013) Poly(ADP-ribosyl)ation links the chromatin remodeler SMARCA5/SNF2H to RNF168-dependent DNA damage signaling. J. Cell Sci. 126, 889-903.

Sone, K., Piao, L., Nakakido, M., Ueda, K., Jenuwein, T., Nakamura, Y., and Hamamoto, R. (2014) Critical role of lysine 134 methylation on histone $\mathrm{H} 2 \mathrm{AX}$ for $\gamma$-H2AX production and DNA repair. Nat. Commun. 5, 5691.

Stelter, P., and Ulrich, H. D. (2003) Control of spontaneous and damage-induced mutagenesis by SUMO and ubiquitin conjugation. Nature 425, 188-191.

Stiff, T., Reis, C., Alderton, G. K., Woodbine, L., O'Driscoll, M., and Jeggo, P. A. (2005) Nbs1 is required for ATR-dependent phosphorylation events. EMBO J. 24, 199-208.

Szilard, R. K., Jacques, P. E., Laramee, L., Cheng, B., Galicia, S., Bataille, A. R., Yeung, M., Mendez, M., Bergeron, M., Robert, F., et al. (2010) Systematic identification of fragile sites via genome-wide location analysis of $\gamma$-H2AX. Nat. Struct. Mol. Biol. 17, 299-305.

Tamburini, B. A., and Tyler, J. K. (2005) Localized histone acetylation and deacetylation triggered by the homologous recombination pathway of double-strand DNA repair. Mol. Cell. Biol. 25, 4903-4913.

Tauchi, H., Kobayashi, J., Morishima, K., Matsuura, S., Nakamura, A., Shiraishi, T., Ito, E., Masnada, D., Delia, D., and Komatsu, K. (2001) The forkhead-associated domain of NBS1 is essential for nuclear foci formation after irradiation but not essential for hRAD50/hMRE11/NBS1 complex DNA repair activity. J. Biol. Chem. 276, 12-15.
Tauchi, H., Kobayashi, J., Morishima, K., van Gent, D. C., Shiraishi, T., Verkaik, N. S., van Heems, D., Ito, E., Nakamura, A., Sonoda, E., et al. (2002a) Nbs1 is essential for DNA repair by homologous recombination in higher vertebrate cells. Nature 420, 93-98.

Tauchi, H., Matsuura, S., Kobayashi, J., Sakamoto, S., and Komatsu, K. (2002b) Nijmegen Breakage Syndrome gene, $N B S 1$, and molecular links to factors for genome stability. Oncogene 21, 8967-8980.

Tissier, A., Kannouche, P., Reck, M. P., Lehmann, A. R., Fuchs, R. P., and Cordonnier, A. (2004) Co-localization in replication foci and interaction of human Y-family members, DNA polymerase poln and REVl protein. DNA Repair 3, 15031514

Toiber, D., Erdel, F., Bouazoune, K., Silberman, D. M., Zhong, L., Mulligan, P., Sebastian, C., Cosentino, C., MartinezPastor, B., Giacosa, S., et al. (2013) SIRT6 recruits SNF2H to DNA break sites, preventing genomic instability through chromatin remodeling. Mol. Cell 51, 454-468.

van Attikum, H., Fritsch, O., and Gasser, S. M. (2007) Distinct roles for SWR1 and INO80 chromatin remodeling complexes at chromosomal double-strand breaks. EMBO J. 26, 41134125 .

Thompson, L. H. (2012) Recognition, signaling, and repair of DNA double-strand breaks produced by ionizing radiation in mammalian cells: the molecular choreography. Mutat. Res. 751, 158-246.

Vassileva, I., Yanakieva, I., Peycheva, M., Gospodinov, A., and Anachkova, B. (2014) The mammalian INO80 chromatin remodeling complex is required for replication stress recovery. Nucleic Acids Res. 42, 9074-9086.

Vidi, P. A., Liu, J., Salles, D., Jayaraman, S., Dorfman, G., Gray, M., Abad, P., Moghem, P. V., Irudayaraj, J. M., Wiesmuller, L., et al. (2014) NuMA promotes homologous recombination repair by regulating the accumulation of the ISWI ATPase SNF2h at DNA breaks. Nucleic Acids Res. 42, 6365-6379.

Wakeman, T. P., Wang, Q., Feng, J., and Wang, X. F. (2012) Bat3 facilitates H3K79 dimethylation by DOT1L and promotes DNA damage-induced 53BP1 foci at G1/G2 cell-cycle phases. EMBO J. 31, 2169-2181.

Watanabe, K., Tateishi, S., Kawasuji, M., Tsurimoto, T., Inoue, H., and Yamaizumi, M. (2004) Rad18 guides poln to replication stalling sites through physical interaction and PCNA monoubiquitination. EMBO J. 23, 3886-3896.

Watanabe, R., Ui, A., Kanno, S., Ogiwara, H., Nagase, T., Kohno, T., and Yasui, A. (2014) SWI/SNF factors required for cellular resistance to DNA damage include ARID1A and ARID1B and show interdependent protein stability. Cancer Res. 74, 2465-2475.

Weemaes, C. M., Hustinx, T. W., Scheres, J. M., van Munster, P. J., Bakkeren, J. A., and Taalman, R. D. (1981) A new chromosomal instability disorder: the Nijmegen breakage syndrome. Acta Paediatr. Scand. 70, 557-564.

Wells, C. E., Bhaskara, S., Stengel, K. R., Zhao, Y., Sirbu, B., Chagot, B., Cortez, D., Khabele, D., Chazin, W. J., Cooper, A., et al. (2013) Inhibition of histone deacetylase 3 causes replication stress in cutaneous $\mathrm{T}$ cell lymphoma. PLoS ONE 8, e68915.

Williams, R. S., Dodson, G. E., Limbo, O., Yamada, Y., Williams, J. S., Guenther, G., Classen, S., Glover, J. N., Iwasaki, H., Russell, P., and Tainer, J. A. (2009) Nbs1 flexibly tethers Ctp1 and Mre11-Rad50 to coordinate DNA double-strand break processing and repair. Cell 139, 87-99.

Woodbine, L., Brunton, H., Goodarzi, A. A., Shibata, A., and Jeggo, P. A. (2011) Endogenously induced DNA double 
strand breaks arise in heterochromatic DNA regions and require ataxia telangiectasia mutated and Artemis for their repair. Nucleic Acids Res. 39, 6986-6997.

Wu, S., Shi, Y., Mulligan, P., Gay, F., Landry, J., Liu, H., Lu, J., Qi, H. H., Wang, W., Nickoloff, J. A., et al. (2007) A YY1INO80 complex regulates genomic stability through homologous recombination-based repair. Nat. Struct. Mol. Biol. 14, 1165-1172.

Wu, X., Ranganathan, V., Weisman, D. S., Heine, W. F., Ciccone, D. N., O'Neill, T. B., Crick, K. E., Pierce, K. A., Lane, W. S., Rathbun, G., et al. (2000) ATM phosphorylation of Nijmegen breakage syndrome protein is required in a DNA damage response. Nature 405, 477-482.

Wurtele, H., Kaiser, G. S., Bacal, J., St-Hilaire, E., Lee, E. H., Tsao, S., Dorn, J., Maddox, P., Lisby, M., Pasero, P., et al.
(2012) Histone H3 lysine 56 acetylation and the response to DNA replication fork damage. Mol. Cell. Biol. 32, 154-172.

Xie, A., Odate, S., Chandramouly, G., and Scully, R. (2010) $\mathrm{H} 2 \mathrm{AX}$ post-translational modifications in the ionizing radiation response and homologous recombination. Cell Cycle $\mathbf{9}$, $3602-3610$.

Yanagihara, H., Kobayashi, J., Tateishi, S., Kato, A., Matsuura, S., Tauchi, H., Yamada, K., Takezawa, J., Sugasawa, K., Masutani, C., et al. (2011) NBS1 Recruits RAD18 via a RAD6-like Domain and Regulates Poln-Dependent Translesion DNA Synthesis. Mol. Cell 43, 788-797.

Zou, L., and Elledge, S. J. (2003) Sensing DNA damage through ATRIP recognition of RPA-ssDNA complexes. Science 300, $1542-1548$. 